\title{
LA IDEA DE PLURALISMO JURÍDICO
}

(Recibido: Marzo 25 de 2011 Aprobado: Mayo 12 de 2011)

Ramiro Ceballos Melguizo**

\section{ResImen}

El presente artículo intenta una caracterización del fenómeno del pluralismo jurídico. Para ello se hace, en primer lugar, una breve síntesis histórica sobre dicha problemática; en segundo lugar, se alude a los contextos sociológicos en los que tienen lugar fenómenos de pluralismo jurídico; en tercer lugar, se propone una síntesis del monismo jurídico, en cuanto interpretación dominante del derecho moderno e idea opuesta al pluralismo jurídico, y se concluye con una distinción terminológica final.

\section{Palahras Have}

Pluralismo jurídico, Síntesis histórica, Sociología, Monismo jurídico.

\section{THE IDEA OF POLITICAL PLURALISM}

\section{Abstract}

The present article attempts to characterize the phenomenon of the pluralism in jurisprudence. Firstly, we will make a brief historical synthesis about this matter. Secondly, we will mention the sociological contexts that take place within this phenomena of pluralism in jurisprudence. In the third place, we propose a synthesis of the judicial monism, with respect to the dominant interpretation of the modern right and as opposed to entering into the judicial pluralism, and we conclude with a brief terminological distinction.

\section{Keywords:}

Judicial Pluralism, Historical Synthesis, Sociology, Judicial Monism.

\footnotetext{
* Artículo de revisión y reflexión filosófica, responde a la línea de investigación de filosofía práctica del grupo de investigación Dianoia.-Filosofía, inscrito en Colciencias con el código COL0042705 del Departamento de Filosofía de la Universidad de Pamplona, para el postgrado en Cultura Política y Educación en su Seminario de Investigación permanente. 2010

** Filósofo y Magíster en Filosofía de la Universidad de Antioquia. Profesor Tiempo Completo, Facultad de Artes y Humanidades Universidad de Pamplona, Colombia. e-mail: ramirocem@yahoo.es
} 


\section{Introducción}

Pluralismo jurídico es el fenómeno de coexistencia de normas que demandan obediencia en un mismo territorio y que pertenecen a sistemas normativos distintos. Aceptando por otra parte que la vigencia de un sistema normativo se basa en una regla de reconocimiento, la Grundnorm de Kelsen, el pluralismo jurídico implica coexistencia de normas que son reconocidas por distintas reglas de reconocimiento. Precisamente esta caracterización genérica, unida al hecho de que el término "pluralismo" comporta evidentes cargas valorativas, hace recomendable entender en adelante la expresión "pluralismo jurídico" como equivalente a pluralidad de órdenes legales.

\section{Antecedentes históricos del pluralismo jurídico}

Es en K. F. Von Savigny (1879) donde se encuentran las primeras ideas sobre el pluralismo jurídico'. Como es sabido, este autor se opuso
Pluralismo jurídico es el fenómeno de coexistencia de normas que demandan obediencia en un mismo territorio y que pertenecen a sistemas normativos distintos.
En las tesis antipositivistas de Eugen Ehrlich (1967) se hallan los puntos clave del pluralismo jurídico, en especial el énfasis en un derecho vivo que existe en la base del derecho institucional y que opera como mecanismo que previene los conflictos y suele también resolverlos cuando ocurren por una vía distinta de las "adjudicaciones", es decir, de las decisiones de una autoridad consagrada constitucionalmente. Ehrlich subraya la existencia de usos y prácticas asociativas que regulan la acción de los individuos de modo autónomo y por delegaciones que el derecho estatal realiza. Estas regulaciones son mucho más determinantes para la armonía social que las propias normas jurídicas como tales.

Con este autor se señala, por vez primera, la coexistencia de ordenamientos plurales en el interior de una misma estructura social, lo mismo que la idea, común desde entonces a todos los teóricos del pluralismo jurídico, de que el Estado no es la única asociación en la que se vive la vida social, aunque sea la germánico a comienzos del siglo XIX, pues ello le parecía un intento de cristalizar criterios inmutables relativos a la convivencia humana, criterios que, según él, debían conservar su plasticidad y adecuación al espíritu del pueblo, histórico y por tanto siempre cambiante. El derecho llevado a los códigos era sólo una representación estática de un proceso permanente que era el de la evolución de la cultura. Para Savigny, la legislación y la ciencia jurídica se consolidan, a través de su complejización y evolución, como una expropiación de la capacidad comunitaria y espontánea del pueblo de crear sus normas de vida. Con esta óptica, aunque profundamente conservadora, previó muchos de los problemas de la moderna y perversa autonomización del derecho. principal. La obra de Ehrlich dio la pauta inicial para la sociología jurídica, esto es, para el estudio del derecho como hecho social y no como mero conjunto de ideas codificadas.

George Gurvitch (1962), por su parte, recoge las influencias de Ehrlich y destaca que la mayoría de los acontecimientos decisivos de la historia del derecho, como la abolición de la servidumbre, la transformación del derecho de propiedad individual, la formación de los sindicatos y de los monopolios, el desarrollo de las convenciones colectivas de trabajo, y otras, se han llevado a cabo independientemente de las proposiciones abstractas del derecho y han sido durante mucho tiempo ignorados por las leyes del Esta- 
do, que sólo con retraso los ha reconocido. Sobre la base de la crítica a Ehrlich, Gurvitch construyó sistemáticamente la más completa teoría del pluralismo jurídico en Francia, exaltando el "derecho social", en el que veía predominar valores de solidaridad y justicia distributiva, frente al "derecho interindividual", basado en la desconfianza y en la dominación y en el que predomina la idea de justicia conmutativa.

El continuador en Francia del camino abierto por Gurvitch fue Henry LévyBruhl (1964), quien apela a los estudios empíricos para probar que existen prescripciones de naturaleza jurídica que no son impuestas por la autoridad pública. Se trata de derechos supra e infranacionales; entre los de naturaleza supranacional señaló los derechos que generan las organizaciones internacionales al igual que el derecho mercantil internacional (/us Mercatorium). A Lévy-Bruhl se debe también la idea de unificación progresiva del derecho en cuanto ideal históricamente realizable: un acuerdo básico sobre ciertos principios fundamentales que tendrían la forma de un derecho común de la humanidad.

Otra figura sobresaliente del pluralismo jurídico en Francia es K. Carbonnier (1969); éste sostuvo que existen distintos fenómenos de pluralismo cuyo punto en común es competir con el orden jurídico estatal. Por ejemplo, los fenómenos de grupos que se dan cuando en un país, por razones históricas, se reúnen elementos provenientes de distintas fuentes. La recepción del derecho romano en Alemania fue un caso de este tipo. Convivieron las prácticas consuetudinarias del antiguo derecho germánico con el sistema de derecho romano. Modernamente este fenómeno se denomina aculturación, situación que se da cuando una cultura extranjera se implanta en una cultura autóctona.

Los modelos de sociedades coloniales deben ser considerados, según Carbonnier, como formas de aculturación, incluida la forma jurídica. Otras formas de pluralismo serían, para este autor, los conflictos entre un derecho lego y un derecho religioso, lo mismo que la supervivencia fáctica de ciertas normas que son abrogadas, pero que siguen conservando de hecho mayor eficacia que las puestas para reemplazarlas. Al jurista italiano Santi Romano (1963) se le considera un representante insigne del pluralismo jurídico. Argumentó que las normas jurídicas no debían identificarse con las normas estatales, pues éstas eran sólo una subespecie de aquellas. El Estado moderno produce un fuerte impulso hacia la unificación de todos los ordenamientos, tanto preestatales como antiestatales; hacia la unificación de las fuentes del derecho en una sola: la Ley. Ello produce la apariencia que el monismo jurídico expresa.

Santi Romano asoció la emergencia de grupos sociales con tendencia a constituirse en círculos jurídicos independientes con la crisis del estado moderno. Hoy en día, como efecto del reordenamiento mundial y la globalización, se observa una "retirada" del Estado, una incapacidad para arbitrar la sociedad, y ello es evocado como causa de la emergencia de ciertas formas de pluralismo. Las comprobaciones de Santi Romano que permitían entender la dinámica de tales grupos ofrecieron un modelo más adecuado para comprender esta realidad. Su idea básica según la cual, al lado de la tendencia del Estado a absorber a los demás ordenamientos, existe también una tendencia de la sociedad a generar 
nuevos órdenes, permanece como un criterio de análisis de las dinámicas de la política moderna y fundamenta el pluralismo jurídico como realidad sociológica.

En el derecho anglosajón, en el derecho del Common Law, las doctrinas del pluralismo jurídico han sido también de enorme trascendencia. Las razones son obvias: es un derecho consuetudinario muy ligado a las prácticas; es más el derecho del precedente que el de la ley; más el derecho del juez que el del legislador; más el derecho del caso, del expediente, que el de la norma abstracta. Por razones de brevedad aludiremos sólo a las posiciones de Marc Galanter (1966) quien recoge los principales asuntos de las problemáticas suscitadas por el pluralismo jurídico en sus estudios sobre la modernización del derecho. Galanter señala la discrepancia que en este proceso se observa entre el modelo hegemónico de un derecho unitario, uniforme y universal, y las múltiples prácticas microsociales, locales, consuetudinarias, frecuentemente incompatibles con el primero. Distingue también entre el derecho de los libros y el derecho en acción. El predominio del primero se asocia con el proceso modernizador, pero la mayoría de las situaciones presentan un tipo intermedio de cristalización legal donde coexisten, con tensiones no resueltas, lo local y lo nacional, lo formal y lo informal, lo oficial y lo popular.

Son ejemplos de tales situaciones las sociedades coloniales y muchos procesos de modernización sobreimpuestos, como los de América Latina, que generan situaciones jurídicas dicotómicas. La conclusión de Galanter es que la modernización no genera un sistema legal que reproduzca los modelos formales en sus detalles. Hay más bien una dialéctica por medio de la cual la modernización, al generar complejidad, genera contrapresiones que reclaman diferenciación, flexibilidad y que obstruyen el proceso de unificación normativa que el derecho formal estatal promueve. Estos son, a grandes rasgos, los asuntos propios de la teoría tradicional del pluralismo jurídico. En el siglo XIX y en las primeras décadas del XX, afirma Boaventura de Sousa Santos (1991), los problemas del pluralismo jurídico se abordaron en el seno de la filosofía y teoría del derecho. Después fueron desapareciendo progresivamente por varias razones:

(....) las transformaciones en la articulación de los modos de producción en el interior de las formaciones capitalistas centrales, de donde resultó el dominio cada vez mayor del modo de producción capitalista sobre los modos de producción precapitalistas; la consolidación de la dominación política del Estado burgués, especialmente a través de la politización progresiva de la sociedad civil y el avance concomitante de las concepciones filosóficas positivistas (p. 69)

\section{Contextos sociológicos del pluralismo jurídico}

En la segunda mitad del siglo $\mathrm{XX}$ el problema del pluralismo jurídico reaparece como motivo de análisis para la antropología y la sociología. Los contextos sociológicos que impulsan una resignificación de los problemas relativos al pluralismo son: la aculturación, el multiculturalismo y la desarticulación social.

\subsection{Aculturación y pluralismo antropológico}

Aculturación es el proceso que se cumple cuando a una cultura autóctona o a una parte de ella se sobreimpone otra 
de origen externo. El resultado de este entrecruzamiento es que la cultura dominada no desaparece. En el campo de la legalidad se presentará seguramente la coexistencia conflictiva de normatividades de origen distinto. En todos los casos de colonialismo se cumplen procesos como éstos. Se presentan entonces regímenes legales ancestrales o tradicionales que algunas veces comportan la abrogación del derecho estatal. Un escenario de pluralismo jurídico con aculturación, aunque sin colonialismo, se da cuando países con tradiciones no europeas adoptan el derecho europeo como instrumento de modernización y de consolidación del Estado. La situación de pluralismo jurídico resulta aquí del hecho de que el derecho tradicional no ha sido eliminado por el nuevo derecho oficial y sigue siendo válido para amplios sectores o para toda la población. Tal fue el caso de Turquía, Tailandia y Etiopía (p. 70). La situación más apremiante y de mayor significación actual en términos de un pluralismo jurídico dado en contextos de aculturación y sometimiento neocolonial es la de las poblaciones indígenas 0 nativas que, no siendo totalmente exterminadas, fueron sometidas al derecho del conquistador y se les permitió conservar en ciertos dominios su derecho tradicional. Es el caso de poblaciones nativas de Norteamérica, América Latina, Nueva Zelandia y Australia (p. 71)

En América Latina, dados los procesos de apertura democrática, se ha venido avanzando en los últimos años en el reconocimiento de la vigencia de normatividades alternas y se ha venido produciendo jurisprudencia que avanza en el reconocimiento y respeto de la diversidad cultural. En Colombia, la Corte Suprema ha producido algunos fallos en los que se revelan avances en este sentido, sin que pueda decirse que no subsisten graves problemas relativos a la precaria situación de las comunidades indígenas, situación que impide tanto su autonomía "jurídica" como su integración en el derecho oficial del Estado, prevaleciendo entonces un fenómeno de pluralismo jurídico desventajoso para las comunidades indígenas.

\subsection{Migración y Multiculturalismo}

Lo extranjero no es hoy, como fue antes, algo excepcional y anecdótico. Vivimos en un mundo de migraciones y movimientos demográficos intensos, flujos de población que obedecen a distintas razones, principalmente a razones socio-laborales o a la búsqueda de protección o asilo a causa de persecuciones políticas o catástrofes ecológicas. No es éste el lugar para abordar el problema de las migraciones y se lo menciona sólo como el motor que impulsa el creciente carácter multicultural del mundo actual. Por su parte, este multiculturalismo plantea el problema de la coexistencia de valores diversos y contrapuestos, ante los cuales surgen preguntas acerca de cómo resignificarlos sin traicionarlos; cómo reconocer y tolerar lo diverso preservando al mismo tiempo lo propio y cómo, en general, neutralizar los fundamentalismos e intolerancias de uno y otro lado. Los problemas de pluralismo jurídico generados en el contexto de la multiculturalidad se refieren específicamente a los conflictos entre los derechos nacionales y estatales y las 
normas de las comunidades minoritarias o migrantes en las que suele prevalecer una mayor fusión entre valores religiosos, morales y propiamente jurídicos. Son, en general, cruzamientos normativos en los que se enfrentan normas jurídicas con normas culturales. Un caso particularmente crítico es el generado por las prácticas de excisión llevadas a cabo por comunidades migrantes en Europa y Estados Unidos, donde la legislación las penaliza según valores distintos a los que inspiran a sus practicantes. Pero muchos otros conflictos transculturales recalan en el escenario jurídico y son motivo de reflexión; algunos de los más virulentos enfrentan valores religiosos que ligan actos cubiertos por la legislación occidental desde un punto de vista secular. A esta problemática podría llamársele la dimensión etnológica del pluralismo jurídico. Pero hay otra más, importante para nosotros los colombianos, por lo que se verá a continuación.

\section{Pluralismo y desarticulación social}

Un caso de pluralismo jurídico de origen no colonial y que tampoco cabe remitir en su origen a un escenario de multiculturalismo es el que se produce en virtud de una revolución social. En estos casos el derecho tradicional entra en conflicto con la nueva legalidad, el derecho revolucionario. Aquel, aunque proscrito, no deja de tener vigor durante cierto tiempo. El caso más conocido es el de las repúblicas de Asia central, de tradición jurídica islámica, en el seno de la URSS, después de la Revolución de octubre (p. 71). Es conjeturable que en todo cambio revolucionario una situación tan compleja como el relevo abrupto de derechos genere una situación temporal de pluralismo jurídico.
Sin embargo, bajo la denominación de escenario o contexto de desarticulación social son abordables, más que revoluciones, situaciones indefinidas de coexistencia conflictiva de normatividades, de las cuales mencionaremos sobre todo tres que son pertinentes o familiares para el caso del país colombiano. La primera es la cuestión de las mafias. Las mafias son también legalidades paralelas, pues generan una normatividad que coexiste con el derecho y puede colocar a muchas personas en situaciones de ambivalencia normativa, al extender sus influencias y la de sus modos de resolver conflictos hasta amplios territorios y variadas relaciones sociales. Este hecho, no suficientemente señalado para el caso de las mafias, es más evidente y crucial cuando se consideran las justicias paramilitares; pero el caso es que también este solapamiento de jurisdicciones es característico del pluralismo referido y no sólo el hecho de que el personal militante de las mafias posea códigos de justicia y de derecho propios.

El segundo caso relevante es el de los grupos paramilitares, los cuales ejercen dominio en distintos territorios conforme a criterios no estatales o, en todo caso, ejerciendo ellos como la verdadera autoridad sancionadora de muchas conductas. Usamos aquí la palabra paramilitar en sentido genérico, de modo que engloba no sólo a grupos mercenarios denominados en Colombia falsa o eufemísticamente como autodefensas, sino también a guerrillas y milicias. Todas estas autoridades paralelas tienden a ejercer unas prácticas de justicia más bien rudimentaria y sumaria, pero también pueden desarrollar códigos y normas muy sofisticados que se constituyen en derechos paralelos y que coexisten de formas muy diversas con el derecho oficial. 
La tercera forma de pluralismo jurídico nacida de un fenómeno de desarticulación social es el relativo a la creación autogestionaria de normas por parte de sectores populares marginales. Se trata de la justicia y el derecho comunitario y campesino en torno de los cuales se ha generado una interesante discusión en la que el problema del pluralismo jurídico se intenta constituir en modelo de un nuevo derecho, opuesto al derecho oficial $^{2}$. Esta normatividad autogestionaria y popular es también el fruto de la desarticulación social, lo mismo que las dos anteriores.

Ello significa que, al generarse muy agudos fenómenos de inequidad social y de deslegitimación e ineficacia del Estado, aparecen formas paralelas o parásitas de autogestión antiestatal o paraestatal, como mafias que saben inmunizarse para sobrevivir, guerrillas que se escudan hábilmente dentro de las poblaciones $y$, finalmente, modos diversos de organizaciones populares que sobreviven en los márgenes de la sociedad y crean sus propios mecanismos de solventación de conflictos, sin recurrir, porque además están excluidas de tal servicio, al derecho del Estado. Hay todavía una fuente más de pluralismo jurídico, aunque no emparentada con el contexto en el que estamos, es decir, con la desarticulación social; se trata de la Lex Mercatoria, un derecho que rige para los negocios transnacionales y coexiste en asocio y en pugna con el derecho de los Estados nacionales. No nos interesa ahora escudriñar en los detalles, pero su prevalencia dimana de la desarticulación del Estadonación y al propio tiempo la agudiza. Aquí sólo queremos mencionarla por cuanto ella permite también un abordaje y relectura del derecho que dan por supuesto el pluralismo en este nivel, esto es, en el de las relaciones interestatales.

\section{Derecho moderno vigente y monismo jurídico}

El derecho positivo estatal de occidente es un modelo formado en Europa a finales del siglo XVI y comienzos del XVII; se basa en cuatro elementos fundamentales que fueron también presupuestos condicionantes de su formación (Ribeiro, 1996, p. 2). El primero es el modo de producción, el capitalismo. Marx elucidó la dinámica interna del mismo como un sistema social de producción donde la fuerza de trabajo, convertida en mercancía, está sometida al capital. Por su parte, Max Weber puntualizó el carácter que tiene el capitalismo de ser la culminación de un proceso de racionalización de la vida organizada.

El segundo presupuesto es el de la formación social, la sociedad burguesa. EI tercer factor es el liberalismo en cuanto visión socio - política del mundo. Ella está constituida por valores, creencias e intereses de la clase social emergente, la burguesía, y provee a la política en general de unos criterios valorativos inspirados en el individualismo y la reciprocidad de los intercambios que se fundan en la lógica egoísta de la apropiación privada de bienes de intercambio y consumo. El liberalismo genera también una ética de promoción para la persona y ha dinamizado poderosamente la búsqueda y sostenimiento de ciertas libertades individuales.

El último presupuesto es la estructura del poder, el Estado soberano y nacional. Se trata de la moderna estructura institucional que, mediante un proceso de centralización, asegura la especificidad de los 
nuevos intereses. Así pues, el modelo del derecho moderno vigente es un modelo capitalista, burgués, liberal y estatal. Ahora veamos cuáles son los presupuestos ideológicos que sustentan esta legalidad moderna y que configuran el modelo de monismo jurídico (p. 3). El primero es la estatalidad según la cual, solamente el sistema legal puesto por el Estado debe ser considerado derecho positivo, no existiendo positividad fuera del Estado y sin él. El Estado detenta así el monopolio de la producción de las normas jurídicas y es por ende la personificación del derecho al ser quien la crea directamente. El segundo principio es el de unicidad, el cual indica que sólo un sistema de normas jurídicas es válido en la sociedad. Precisamente, se trata de las normas producidas por el Estado para regular los intereses de una comunidad nacional.

De esta unicidad se desprende el criterio de la seguridad jurídica, dada por la jerarquía de la autoridad legal establecida en dicha jurisdicción nacional y que funda a su vez una idea dogmática de la normatividad, sobre la que retornaremos aquí mismo más adelante. El tercer presupuesto es el principio de la positividad. Según él, todo derecho se reduce a un conjunto de normas coercitivas vigentes y a los mecanismos formales sostenidos por una organización centralizada que asegura su cumplimiento. En otras palabras, la positividad dice que sólo es válida la norma dictada por el legislador autorizado, el Estado. Pero, por eso mismo, este principio avala la sanción establecida no siempre legítimamente y tiende a reducir el derecho al orden vigente.

El cuarto principio es el de la racionalidad. El fenómeno de la racionalización es el presupuesto esencial para la correcta comprensión de los aspectos normativos, institucionales y decisionales del derecho occidental moderno. La racionalidad es, en términos weberianos, la organización de la vida conforme a la división y coordinación de las diversas actividades, con base en el estudio preciso de las relaciones entre los humanos, sus instrumentos y sus medios con miras a una mayor eficacia y rendimiento. La racionalidad del derecho moderno se expresa como tendencia a reducir las relaciones humanas a los criterios de organización de la producción y, en cuanto tal, el derecho tiende a convertirse en una administración racional legal de la vida. EI privilegio de los medios sobre los fines, propio de la racionalidad formal del Estado capitalista, busca clasificar las normas jurídicas por la manera como son decididas y no por su contenido, forzando así la universalización de las reglas jurídicas. El derecho tiende por ello a convertirse en mero instrumento de racionalización, sujeto a los criterios de una sociedad que no gira en torno a la justicia, esto es, a la satisfacción del derecho, sino a la eficacia de su funcionalidad como sistema de rendimiento.

Al respaldo del derecho moderno vigente se encuentran, pues, las ideas monistas de la dogmática jurídica que tienden a convertir la ciencia jurídica en una axiomática, de la cual sería posible deducir soluciones concretas en el marco de un sistema cerrado de racionalidad técnico-jurídica. Este tipo de concepciones, haciendo explícita la lógica implícita en el movimiento de codificación, y más remotamente, en el proyecto constitucional del Estado liberal, llevan al extremo el principio de legitimación asentado en la 
racionalidad jurídico-formal, formulado por Max Weber para caracterizar el fundamento de la autoridad política del Estado moderno (Santos, 1991, p. 26)

\section{Conclusión}

El pluralismo jurídico es entonces un fenómeno central de la problemática de constitución y deconstrucción

El pluralismo del Estado liberal jurídico es entonces moderno. Es, en un fenómeno

central de la problemática de constitución y deconstrucción del Estado liberal moderno. el fondo, el producto de lecturas realistas, inspiradas en las filosofías antiliberales $y$ en las ciencias sociales, que en el registro de los hechos jurídicos cuestionan la ideología liberal de un Estado, una

autoridad y un derecho, como dogmas de la política en la sociedad moderna occidental. Para concluir conviene hacer la siguiente aclaración terminológica: una cosa es el pluralismo jurídico, y otra, estos dos fenómenos que pueden confundirse o no diferenciarse lo suficiente a saber: el derecho alternativo y el uso alternativo del derecho ${ }^{3}$. Pluralismo jurídico es la coexistencia de normas que reclaman obediencia en un mismo territorio y que pertenecen a sistemas distintos.

Por derecho alternativo se entiende, en cambio, un sistema normativo cuyas normas obligan a producir conductas que, conforme con el sistema hegemónico, constituyen delito o formas menores de faltas. Derecho alternativo significa, entonces, la existencia de un fenómeno de pluralidad jurídica, en tanto que lo inverso no siempre es verdadero. Así, hay alternatividad cuando la coexistencia de derechos no es pacífica; pero habría, en este aspecto, una ulterior distinción posible además: la de una alternatividad emancipatoria, como en el caso de los derechos de movimientos de liberación, y una alternatividad no emancipatoria, como el choque del Estado con las mafias.

(...)Uso alternativo del derecho, por su parte, es la interpretación y uso del sistema normativo hegemónico de manera que se consigan decisiones favorables a los intereses de ciertos sectores sociales a los cuales el derecho oficial desfavorece de hecho. Es una práctica comprometida de ciertos operadores jurídicos que intenta democratizar el servicio de la justicia, extendiéndolo a grupos marginales, usando de esta forma la práctica jurídica como instrumento político de lucha (Garzón, 1996, p. 87 ss)

\section{Notas}

${ }^{1}$ En la exposición de antecedentes y contexto del pluralismo jurídico sigo la excelente síntesis que de tales problemas hace CÁRCOVA, C. (1998) La opacidad del derecho. Madrid: Trotta. 1998. p. 61, ss.

${ }^{2}$ Sobre la discusión filosófica del pluralismo y el derecho alternativo véase CÁRCOVA, C. Op. cit. p 91, ss.

${ }^{3}$ Revisar: CORREAS, O. (1994) La teoría general del derecho y el derecho alternativo. En: Revista El otro derecho. Ilsa. Bogotá. No 5 Vol. 3.

\section{Referencias}

CÁRCOVA, C. (1998) La opacidad del derecho. Madrid: Trotta. 1998.

CARBONNIER, K. (1969) Flexible Droit, textes pour une sociologie du droit sans rigueurs. Paris: Librairie générale de droit et de jurisprudence.

CORREAS, O. (1994) La teoría general del derecho y el derecho alternativo. En: Revista El otro derecho. Ilsa. Bogotá. N 5 Vol. 3.

EHRLICH, E. (1967) Fundamentes da sociología do direito. Brasil: Universidade de Brasilia.

GALANTER, M. (1966) The modernization of law, in Myron Weiner, ed., Modernization: The Dynamics of Growth. New York: Basic Books

GARZÓN, E., y LAPORTA, F. (1996) El derecho y la justicia. Madrid: Trotta.

GURVITCH, G. (1962) Tratado de sociología. Buenos 
Aires: Ed. Capeluzs.

LÉVY-BRUHL, H. (1964) Sociología del derecho. Universidad de Buenos Aires: Eudeba.

RIBEIRO, F. (1996) Pluralismo Jurídico. Análise e critica a esta nova doutrina emergente. Universidade Federal de Santa Catarina.-UFSC- Centro de ciências jurídicas -CCJ-florianópolis.

ROMANO, S., MARTÍN, S. (1963) El ordenamiento jurídico. España: Instituto de Estudios Políticos.

SANTOS, B. (1991) Estado, derecho y luchas sociales. Bogotá: Ilsa.

VON SAVIGNY, K. (1879) El sistema del Derecho romano. Biblioteca de Catalunya: F. Góngora. 